\title{
Pediatric multiple sclerosis in Venezuela
}

\author{
Esclerosis múltiple pediátrica en Venezuela \\ Joaquin A. Peña', María Elena Ravelo², Evelio Rubio ${ }^{3}$, Dulce Pirela ${ }^{4}$, Arnoldo Soto ${ }^{3}$, Cecilia Montiel Nava ${ }^{5}$
}

\begin{abstract}
Objective:To describe the epidemiological and clinical characteristics of Venezuelan pediatric patients with multiple sclerosis (MS). Methods: Database records from the National Program for MS were searched for patients with an established diagnosis of MS whose first symptoms appeared before age 18. Results: The national database held records of 1.710 patients; $3.8 \%$ had onset of the first symptoms before age 18. 46.7\% were boys, yielding an F:M ratio of 1.13:1. Many children had a disease onset characterized by motor impairment (30.7\%), brainstem/ cerebellum and spinal cord affectation (27.6\%), headache (26\%). Less frequent symptoms were sensory symptoms (8\%) and optic neuritis (7\%). Discussion: Pediatric MS patients in Venezuela represent a significant proportion of all MS cases. The clinical pattern is characterized by motor symptoms at onset, and predominantly monosymptomatic presentation with a relapsing-remitting pattern. This is the first systematic attempt to estimate the prevalence of pediatric MS in Venezuela.
\end{abstract}

Key words: multiple sclerosis, demyelinating disorders, children, epidemiology.

\section{RESUMEN}

Objetivo: Describir las características clínicas y epidemiológicas de pacientes pediátricos venezolanos con EM. Métodos: Se revisó la base de datos del Programa Nacional para EM, identificando pacientes con diagnóstico establecido de EM antes de los 18 años de edad. Resultados: La base de datos registró 1.710 pacientes y 3,8\% tenía una edad de aparición menor de 18 años. De estes, 46,7\% eran varones, dando una relación F:M de 1.13:1. Muchos niños tuvieron una aparición de la enfermedad caracterizada por déficit motor (30,7\%), afectación del tronco encefálico-cerebelo y la médula espinal (27,6\%), dolor de cabeza (26\%). Síntomas menos frecuentes fueron sensoriales (8\%) y neuritis óptica (7\%). Discusión: Los pacientes pediátricos venezolanos con MS representan una proporción significativa de todos los casos de MS. El patrón clínico está caracterizado por síntomas motores y presentación predominantemente monosintomática con patrón brote-remisión. Este es el primer intento sistemático para estimar la prevalencia de MS pediátrica en Venezuela.

Palabras-Clave: esclerosis múltiple, trastornos desmielinizantes, niños, epidemiología.

Multiple sclerosis (MS) is a demyelinating disorder of the central nervous system and the most common disabling neurological disorder in young adults ${ }^{1,2}$. It is clinically characterized by a variety of neurological signs and symptoms which are attributed to white matter lesions. Those lesions are disseminated in time and space. Clinical signs may appear in sudden attacks or be insidious and progressive ${ }^{3,4}$. The diagnosis of pediatric MS has been largely overlooked by pediatricians and pediatric neurologists ${ }^{5,6}$, who have long regarded it as a rare disease. Recently, there is emerging evidence which proves that MS can manifest in childhood and adolescence. In addition, the challenges in its differential diagnosis make the diagnosis in this age group a difficult task ${ }^{7}$. Other disorders, including leukodystrophies and metabolic diseases, may masquerade the clinical picture of MS in pediatric patients. Furthermore, children with MS may present with clinical symptoms that can hardly be distinguished from acute disseminated encephalomyelitis (ADEM) $)^{5,8,9}$.

Several reviews of the MS epidemiology reveal prevalence estimates of pediatric onset MS ranging from 2.7 to $10.5 \%$ of all people with $\mathrm{MS}^{5,10}$. However, most studies on pediatric MS come from high -risk areas and little is known about this disorder in Latin America ${ }^{11}$. Only three retrospective studies, two in Brazil ${ }^{12,13}$ and one in Venezuela ${ }^{14}$, have dealt with demographics and epidemiological characteristics of children with MS. In Venezuela, Peña et al. ${ }^{14}$ reported on the demographics

${ }_{1}^{1}$ Pediatrics Department, School of Medicine, University of Zulia, Maracaibo, Venezuela;

${ }^{2}$ Neuropediatrics Service, JM de los Rios Pediatric Hospital, Caracas, Venezuela;

${ }^{3}$ Hospital El Llanito, Venezuelan Institute of Social Security, Caracas, Venezuela;

${ }^{4}$ Pediatrics Department, School of Medicine, University of Zulia, Maracaibo, Venezuela;

${ }^{5}$ Psychology Department, School of Education, University of Zulia, Maracaibo, Venezuela.

Correspondence: Joaquín A. Peña; Urbanización Canaima Calle 42, 15-18 Maracaibo, Estado Zulia - Venezuela; E-mail: juaco949@hotmail.com, juaco949@gmail.com

Conflict of interest: There is no conflict of interest to declare.

Received 15 September 2011; Received in final form 06 October 2011; Accepted 13 October 2011 
and clinical feature of 11 Venezuelan patients and comparing them with those of 46 patients with ADEM. The results of this study yielded an estimated overall rate of MS about $4.5 / 100,000$, with $2.5 \%$ for the pediatric age. To our knowledge, no other studies have been conducted in our region with pediatric patients.

Diagnostic and treatment services for children with MS have been developed in many countries ${ }^{10,15,16}$, while there is a significant lack of resources in others ${ }^{11,17}$. It is important to gather more precise information about the extent of the disease regarding demographics and its clinical course in the pediatric age group. Such information will help in providing adequate services for these children. The aim of this study was to describe the epidemiological and clinical characteristics of Venezuelan pediatric patients with MS.

\section{METHODS}

All Venezuelan patients with inflammatory diseases of the central nervous system are registered in a database of the National Program for Multiple Sclerosis which is administrated by the Venezuelan Institute of Social Security (IVSS, Caracas). The Venezuelan national MS registry is a comprehensive database of all MS patients which includes the information about first clinical event, lab tests, neuroimaging and course of the disease. That information allows for the study of epidemiological variables, such as demographics and clinical profile. These registries are implemented to facilitate the correct distribution

Table 1. Age distribution.

\begin{tabular}{lcc} 
Age group & Number of cases & $\%$ \\
\hline $0-2$ & 0 & 0 \\
$2-6$ & 5 & 7.6 \\
$6-10$ & 8 & 12.3 \\
$10-14$ & 16 & 24.6 \\
$14-18$ & 36 & 55.5 \\
Total & 65 & 100 \\
\hline
\end{tabular}

Table 2. Clinical symptoms.

\begin{tabular}{lcc}
\multicolumn{1}{c}{ Clinical symptoms } & Number of cases & $\%$ \\
\hline Hemiparesis & 20 & 30.76 \\
Paraparesis & 18 & 27.69 \\
Ataxia & 18 & 27.69 \\
Cephalea & 17 & 26.15 \\
Paresthesia & 10 & 8.13 \\
Optic neuritis & 9 & 7.32 \\
Diplopia & 9 & 7.32 \\
Urinary incontinence & 7 & 5.69 \\
Facial paralysis & 6 & 4.88 \\
Dysarthria & 3 & 2.44 \\
Alterations of consciousness & 2 & 1.63 \\
Tremors & 1 & 0.81 \\
Dysmetria & 1 & 0.81 \\
Seizures & 1 & 0.81 \\
\hline
\end{tabular}

of disease, modifying therapy among Venezuelan MS patients. These drugs are provided free of charge to every patient that fulfills the diagnostic criteria for MS. Database records with a MS history form, collected from August 1993 to August 2010, were searched for patients with an established diagnosis of MS whose first symptoms regarding a demyelinating event appeared below the age of 18 years. For the purposes of this study, the International Pediatric MS Study Group consensus diagnostic criteria were used to define Pediatric $\mathrm{MS}^{5}$.

\section{RESULTS}

By the time of the study, the complete national database held records of 1.710 patients diagnosed with MS. From this group, 65, which correspond to $3.8 \%$, had an age of onset of the first symptoms consistent with a demyelinating event below 18 years of age. As it is shown in Table 1, the vast majority of patients belonged to the adolescent age group $(n=36$, $55.5 \%)$. Symptoms onset was below 10 years of age for 13 children (19.9\%), between 10 and 14 years of age for 16 children (24.6\%), and for 36 children (55.5\%) in the range of 15-18 years. It seems that the proportion of children diagnosed with MS increased with age. From the total pediatric sample ( $n=65), 31$ (46.7\%) were boys, yielding a F:M ratio of 1.13:1 for the entire group, with a higher number of females in the adolescent group. Regarding race and ethnicity characteristics, all patients were mestizos or white non-caucasians, with absence of native amerindian or afro american children.

As exhibited in Table 2, many children had a disease onset characterized by motor impairment $(n=20,30.7 \%)$, brainstem/cerebellum and spinal cord affectation $(n=18$, $27.6 \%)$, headaches $(n=17,26 \%)$. Less frequent symptoms at onset were sensory symptoms $(n=10,8 \%)$ and optic neuritis $(n=9,7 \%)$. Polysymptomatic presentation with encephalopathy was observed in 2 patients from the younger group ( $<10$ years of age). One patient presented with seizures; and another one had a diagnosis of primary progressive MS; while the remainder had a diagnosis of relapsing-remitting MS (RRMS) (n=64, 98.4\%).

\section{DISCUSSION}

In the present study, the estimated prevalence of pediatric onset MS in Venezuela was $3.8 \%$ of all MS cases. This number is very close to those previously reported in other countries ${ }^{1,3,15,16,18}$. We defined pediatric MS using 18 years as a cut point according to the consensus definitions published by the International Pediatric MS Study Group in $2007^{5}$. Other studies have used variable definitions and onset below 16 years, indicating that the estimated prevalence in our country would probably be less than that reported. However, 
our study provides an estimate of the actual prevalence of pediatric onset MS in Venezuela, as the MS National Program received all the patients with MS diagnosis at the time of the study. So, we consider this as the best estimate of pediatric MS in our country, since we sampled the total of known cases at the time of the study. Obviously, case ascertainment in pediatric MS represents a significant factor affecting estimations of the prevalence ${ }^{17}$.

The female to male ratio in our series was 1.13:1 for the entire group, being dependent on the age at the manifestation of the disorder. For children older than 14 years, we found a female predominance, which resembles the gender proportions that are usually seen in adult MS. This greater number of females than males is one of the most consistent findings in the MS literature ${ }^{3,15,16,18,19}$, which points toward a possible role for puberty hormonal changes that modulate the immunological state ${ }^{10,15,19}$. We also observed that the prevalence of pediatric MS was higher in the adolescent age group, which is consistent with other studies. These findings might be explained by an eagerness to reach the diagnosis in older children in comparison with the younger ones. Also, it is possible that older children might present more clinical episodes which helps clarify the diagnosis of MS. Most of the patients were mestizos and white non-caucasian, probably reflecting the ethnic characteristics of our country ${ }^{20}$.

We found a high rate of motor impairment and brainstem/cerebellum signs at disease manifestation about $30 \%$ each, followed by sensory symptoms and optic neuritis (10\%). In addition, headache was seen in about $25 \%$ of patients at onset. Boiko et al. ${ }^{18}$, in their series of 116 pediatric patients, reported that only $10 \%$ presented with weakness. Brainstem dysfunction and sensory disturbances were the initial presentation in about 13 and $26 \%$ of their patients, respectively. In the Italian study, $25 \%$ of patients presented with brainstem dysfunction; motor and sensory symptoms were presented by 18 of patients at onset ${ }^{16}$. An earlier German nationwide study reveals that 44, 30 and 29\% of pediatric patients displayed cerebellar signs, brainstem and motor signs at onset, respectively ${ }^{21}$. More recently, in a Brazilian study among the initial presentation, there was a predominance of motor impairment (38\%) and brainstem/ cerebellum $(22.5 \%)^{13}$. Therefore, our patients displayed a higher frequency of motor and brainstem/cerebellum signs than the majority of studies. However, direct comparisons are difficult due to the methodological differences among case definitions and patients ascertainment in the different studies. Like in other reports on pediatric MS, the vast majority of patients presented with a relapsing-remitting course of the disease and only one patient had a diagnosis of primary progressive MS. It has been proposed by many authors that disease progression is slower and more delayed in pediatric MS patients in comparison to adult MS patients ${ }^{4}$. It appears that recovery after a clinical exacerbation is shorter in children than in adults, and a lower proportion of children are classified with progressive forms of the disease.

The results of this study need to be interpreted with caution. It is possible that a prevalence rate of pediatric MS in Venezuela of $3.8 \%$ might be an underestimation, since the sample only included those patients who were receiving disease modifying therapy. On the other hand, using the national MS registry, this sample covers all the cases diagnosed, documented and registered in the country at the time of the study. In that way, we considered it as the best current estimation of MS prevalence and epidemiological data of pediatric MS in Venezuela. Furthermore, this information adds to the scarce body of literature of pediatric MS in Latino children.

In conclusion, pediatric MS patients in Venezuela represent a significant proportion of all MS cases. The clinical pattern is similar to the pattern reported in other parts of the world, which is characterized by motor symptoms at onset and predominantly monosymptomatic presentation with a relapsing-remitting pattern. This is the first systematic attempt to estimate the prevalence of pediatric MS in Venezuela. The study provides a foundation for future epidemiological studies with larger samples and better case ascertainment, and will allow establishing a better characterization of pediatric MS patients and the identification of its risks and etiological factors.

\section{References}

1. Duquette P, Murria TJ, Pleines J, et al. Multiple sclerosis in childhood:clinica profile in 125 patients. J Pediatric 1987;111: 359-363.

2. Hanefeld F. Pediatric multiple sclerosis: a short history of a long history. Neurology 2007;68(Suppl 2)S3-S6.

3. Sindern E, Hass J, Stark E, et al. Early onset MS under the age 16: clinical and paraclinical features. Acta Neurol Scand 1992;86: 280-284.

4. Chabas D, Green AJ, Waubant E. Pediatric multiple sclerosis. NeuroRx 2006;3:264-275.
5. Krupp L, Banwell B, Tenembaum S. Consensus definitions proposed for pediatric multiple sclerosis and related disorders. Neurology 2007;68(Suppl 2): S7-S12.

6. Gadoth N. Multiple sclerosis in children. Brain Dev 2003;25:229-232.

7. Ness JM, Chabas D, Sadovnick AD, Pohl D, Banwell B, WeinstockGuttman B. Clinical features of children and adolescents with multiple sclerosis. Neurology 2007;68(Suppl 2):S37-S45.

8. Simone IL, Carrara D, Tortorella C, et al. Course and prognosis in early-onset MS: comparison with adult-onset forms. Neurology 2002;59:1922-1928. 
9. Hyson JL, Kornberg AJ, Coleman LT, Shield L, Harvey AS, Kean MJ. Clinical and neuroradiologic features of acute disseminated encephalomyelitis in children. Neurology 2001;56:1308-1312.

10. Banwell B, Ghezzi A, Bar-Or A, Mikaeloff Y, Tardieu M. Multiple sclerosis in children: clinical, diagnosis, therapeutic strategies, and future directions. Lancet Neurol 2007;6:887-902.

11. Tenembaum S, Moreira M, Morales NM, et al. Lactrims Pediatrics Group. Clinical and demographic features of pediatric multiple sclerosis: preliminary data from a Latin American multinational collaborative study group. Multiple Sclerosis 2008;14:S202.

12. Guihoto LM, Osório CA, Machado LR, et al. Pediatric multiple sclerosis report of 14 cases. Brain Dev 1995;17:9-12.

13. Ferreira ML, Machado MI, Dantas MJ, Porto AJ, Souza AM. Pediatric multiple sclerosis. Analysis of clinical and epidemiology aspects according to National MS Society Consensus 2007. Arq Neuropsiquitr 2008;66:665-670.

14. Peña JA, Montiel-Nava C, Ravelo ME, González S, Mora LaCruz E. Esclerosis múltiple en niños: clarificando su evolución dentro del espectro desmielinizante. Invest Clin 2006;47: 413-425.
15. ChitnisT, Glanz B, Jaffin S, Healy B. Demographics of pediatric-onset multiple sclerosis in an MS center population from the Northeastern United States. Mult Scler 2009;15:627-631.

16. Ghezzi A, Deplano V, Faroni J, et al. Multiple sclerosis in childhood: clinical features of 149 cases. Multiple Sclerosis 1997;3:43-46.

17. El-Salem K, Al-Shimmery E, Horany K, Al-Refai A, Khader Y. Early onset multiple sclerosis in Jordan: a retrospective analysis. J Pediatr Neurol 2006;4:155-160.

18. Boiko A, Vorobeychik G, Paty D, Devonshire V, Sadovnick D. Early onset multiple sclerosis: a longitudinal study. Neurology 2002;59: 1006-1010.

19. Stark W, HuppkeP, Gärtner J. Paediatric multiple sclerosis: the experience of the German Centre for Multiple Sclerosis in Childhood and Adolescence. J Neurol 2008;255(Suppl 6):S119-S122.

20. Peña JA, Ravelo ME, Mora La Cruz E, Montiel-Nava C. NMO in pediatric patients: brain involvement and clinical expression. Arq Neuropsiquiatr 2011;69:34-38.

21. Pohl D, Hennemuth I, von Kries R, Hanefeld F. Paediatric multiple sclerosis and acute disseminated encephalomyelitis in Germany: results of a nationwide survey. Eur J Pediatr 2007;166:405-412. 